\title{
Pre-emptive lumbar epidural anaesthesia reduces postoperative pain and patient-controlled morphine consumption after lower abdominal surgery
}

\author{
Joel Katz ${ }^{a, c, d, *}$, Michel Clairoux ${ }^{\text {b,1 }}$, Brian P. Kavanagh ${ }^{\text {b,d }}$, Sandra Roger ${ }^{\text {b }}$, Hilary Nierenberg ${ }^{\text {, }}$, \\ Cormac Redahan ${ }^{b}$ and Alan N. Sandler b,d \\ Departments of ${ }^{a}$ Psychology and ${ }^{b}$ Anaesthesia, The Toronto Hospital, Toronto, MSG 2 C4 Ontario (Canada) and Departments of ${ }^{c}$ Behavioural \\ Science and ${ }^{d}$ Anaesthesia, University of Toronto, Toronto, Ontario M5S IA8 (Canada)
}

\begin{abstract}
Summary
The present study tested the hypothesis that patients receiving epidural bupivacaine before surgery would require less morphine postoperatively and/or report less intense pain than patients receiving epidural bupivacaine after incision but before the end of surgery. Forty-two patients (ASA class I-III) scheduled for lower abdominal surgery were randomly assigned to 1 of 2 groups of equal size and prospectively studied using a double-blind, placebo-controlled crossover design. Epidural catheters were placed in the T12-L1 or L1-L2 interspaces pre-operatively, the position of the catheter was confirmed with $3 \%$ chloroprocaine with epinephrine $1: 200,000$, and sensory testing was carried out until levels had receded to below T12. Group 1 received $15 \mathrm{ml}$ of $0.5 \%$ epidural bupivacaine injected $35 \mathrm{~min}$ before incision followed by $15 \mathrm{ml}$ of epidural normal saline $30 \mathrm{~min}$ after incision. Group 2 received $15 \mathrm{ml}$ of epidural normal saline injected $37 \mathrm{~min}$ before incision followed by $15 \mathrm{ml}$ of $0.5 \%$ epidural bupivacaine $30 \mathrm{~min}$ after incision. General anaesthesia was induced with thiopental $(4-6 \mathrm{mg} / \mathrm{kg})$ and maintained with $\mathrm{N}_{2} \mathrm{O} / \mathrm{O}_{2}$ and isoflurane. Paralysis was achieved with pancuronium $(0.1 \mathrm{mg} / \mathrm{kg})$. Opioids were not used as pre-medication or during surgery. Postoperative analgesia consisted of patient-controlled (PCA) intravenous morphine. Visual analogue pain scores (VAS) (at rest and after standardized mobilization) did not differ significantly between the 2 groups but McGill Pain Questionnaire (MPQ) pain ratings were significantly lower in group 1 at the 24 and $72 \mathrm{~h}$ assessments. Group 1 used significantly less morphine than did group 2 between 12 and $24 \mathrm{~h}$ after surgery. Cumulative PCA morphine consumption in group $1(55.2 \pm 4.7 \mathrm{mg})$ was significantly lower than in group $2(71.7 \pm 6.1 \mathrm{mg}) 24 \mathrm{~h}$ and $48 \mathrm{~h}$ (group 1: $86.8 \pm 6.3 \mathrm{mg}$ vs. group 2: 108.9 $\pm 9.8 \mathrm{mg}$ ) after surgery, but not at the $72 \mathrm{~h}$ assessment. Reduction in morphine dose at 24,48 and $72 \mathrm{~h}$ amounted to $30 \%, 25 \%$ and $22 \%$, respectively. The results suggest that single-shot pre-emptive epidural local anaesthesia is associated with a short-term morphine-sparing effect which is most pronounced between 12 and $24 \mathrm{~h}$ after surgery. Extending the pre-operative blockade into the postoperative period may prolong the initial advantage conferred by pre-emptive epidural local anaesthesia.
\end{abstract}

Key words: Epidural bupivacaine; Patient-controlled analgesia; Morphine; Surgery, abdominal; Pre-emptive analgesia; Inflammation

\footnotetext{
* Corresponding author: Joel Katz, Department of Psychology, The Toronto Hospital, General Division, 200 Elizabeth St., CW 2-306, Toronto, Ontario M5G 2C4, Canada. Tel.: (416) 340-3777. FAX: (416) $340-4739$.

1 Present address: Département d'anesthésie et réanimation, CHUS, 300112 ième avenue nord, Fleurimont, Québec J1H 5N4, Canada.
}

\section{Introduction}

There has been considerable interest in pre-emptive analgesia since Wall (1988) raised the possibility that pain after surgery might be reduced by preventing intra-operative nociceptive impulses from reaching the spinal cord. The significance of this approach lies not only in the obvious immediate benefit of protecting the 
patient at the time of surgical trauma but also in the possibility that such pre-treatment will prevent the development of specific central neural changes which later amplify the peripheral signal and contribute to heightened postoperative pain (Wall 1989; Woolf 1991). The scientific basis for pre-emptive analgesia derives from animal studies showing that the prolonged behavioural and physiological sequelae which normally develop after brief noxious stimuli could be prevented by pre-injury administration of opioids or local anaesthetics (Woolf and Wall 1986; Dickenson and Sullivan 1987; Coderre et al. 1990). In contrast, the same treatments are less effective when administered after the central hyperexcitability or pain behaviours have been established.

Although initial studies of pre-emptive analgesia showed that pre-operative blockade with local anaesthetics or pre-operative administration of systemic opioids was more effective in reducing postoperative pain than control conditions involving no treatment, the results of subsequent investigations comparing the effects of pre-operative treatment with the same treatment initiated after surgery have produced inconsistent results (see McQuay 1992; Coderre et al. 1993; Dahl and Kehlet 1993; Woolf and Chong 1993, for recent reviews). The reasons for the lack of consistency are not clear. Studies showing that postoperative pain can be pre-empted have generally found small, albeit significant, reductions in pain or postoperative analgesic consumption, suggesting that the contribution of sensitized central neurones to the total postoperative pain experience may be overshadowed by the more salient peripheral input (Katz et al. 1992). However, negative studies often include pre-operative or intra-operative opioids as part of the general anaesthetic regimen which may have the unintended effect of pre-empting pain in all patients. Other possibilities include the potential pre-emptive analgesic effects of other agents used routinely as part of the general anaesthetic and the role of postoperative inflammation in initiating and maintaining a state of central sensitization.

In a recent study of patients scheduled for thoracic surgery, Katz et al. (1992) found that pre-incisional epidural fentanyl $(4 \mu \mathrm{g} / \mathrm{kg})$ resulted in lower pain scores $6 \mathrm{~h}$ after surgery and reduced morphine consumption between 12 and $24 \mathrm{~h}$ after surgery when compared with epidural fentanyl $(4 \mu \mathrm{g} / \mathrm{kg})$ administered $15 \mathrm{~min}$ after incision. These findings were discussed in terms of technical and methodological factors which may have minimized the pre-emptive effect and reduced the inter-group differences in postoperative pain and morphine consumption. Specifically, use of lumbar (rather than thoracic) epidural catheters for thoracic surgery, use of a short-acting opioid instead of a local anaesthetic, and administration of the epidural fentanyl after only $15 \mathrm{~min}$ of surgical trauma in the postincisional group may have reduced the magnitude of the pre-emptive analgesic effect.

In the present study, we addressed these factors in an attempt to improve upon the results of the previous study. Thus, we (1) matched the level of the surgery (lower abdominal) with the level of the epidural catheter (lumbar) in order to maximize the probability of an effective blockade, (2) used epidural bupivacaine, instead of fentanyl, to prolong the duration and improve the density of the blockade and (3) extended the unblocked interval to $30 \mathrm{~min}$ between incision and administration of bupivacaine for patients in the postincisional group. The present study used a randomized, double-blind, placebo-controlled, crossover design in which patients undergoing lower abdominal surgery received lumbar epidural bupivacaine or saline before surgery or $30 \mathrm{~min}$ after incision. Based on our previous results, we hypothesized that pre-incisional epidural bupivacaine would be associated with a significant postoperative morphine-sparing effect and/or lower pain scores when compared with postincisional epidural bupivacaine.

\section{Materials and methods}

Approval to carry out the study was obtained from the Toronto Hospital Committee for Research on Human Subjects. All patients gave their written informed consent to participate before entering the study.

\section{Sample size estimation}

Prior to the start of the study, we estimated that a sample size of 21 patients per group would be required to detect an inter-group mean difference in postoperative PCA morphine consumption of 14 $\mathrm{mg}( \pm 3.7 \mathrm{mg}$ pooled SEM) in the 12 -h period between 12 and $24 \mathrm{~h}$ after completion of surgery using a type $I$ error rate of 0.05 and a type II error rate of 0.1 (i.e.. power $=0.9$ ). These data were obtained from our previous study of pre- versus postincisional epidural fentanyl (Katz et al. 1992).

\section{Patient selection}

Patients scheduled for lower abdominal surgery through a midline incision (ASA physical status 1-III) were included in the study. Exclusion criteria were contra-indications to regional anaesthesia. ASA physical status greater than 3, age older than 76 years, weight heavier than or equal to $100 \mathrm{~kg}$, and chronic pain problems.

\section{Randomization and blinding procedures}

A randomization schedule was generated specifying the group (1 or 2) to which each prospective patient would be assigned upon entry into the trial (Dallal 1988). An envelope containing the group assignment (and the order of bupivacaine and saline administration) was prepared, sealed and numbered for each prospective patient. On the morning of the surgery, an anaesthesiologist who was not involved in the study, opened the patient's envelope, read its contents, and prepared two identical syringes that were labelled for pre-incisional and postincisional epidural injections. One syringe contained $15 \mathrm{ml}$ of $0.5 \%$ bupivacaine and the other $15 \mathrm{ml}$ of normal saline.

All patients and personnel involved in patient management and 
data collection were unaware of the group to which the patient had been assigned. The anaesthesiologist in charge of the case was also unaware of the patient's group but had ready access to this information in the event of an emergency. The anaesthesiologist in charge of the case was not involved in the patient's postoperative care or data collection.

\section{Pre-operative assessment}

The day before surgery, patients were interviewed by a member of the Acute Pain Research Unit. Patients were familiarized with the visual analogue (VAS) pain scale and were introduced to the PCA pump and carefully instructed in its use.

\section{Anaesthesia}

Epidural anaesthesia. Patients received midazolam (2-4 mg, i.v.) as sedation for placement of the epidural catheter. Using the loss of resistance technique, epidural catheters were placed via the T12-L1 or L1-L2 interspaces pre-operatively and advanced 3-4 cm cephalad. The position of the catheter was tested with $3 \mathrm{ml}$ of $3 \%$ chloroprocaine with epinephrine $1: 200,000$ to exclude subarachnoid and intravascular insertion. If the patient did not report paresthesia or warmth in the lower extremities $10 \mathrm{~min}$ after the test dose, another 1-2 ml was injected. With this regimen, all patients manifested some degree of sensory and/or motor blockade to pinprick. Sensory level and motor blockade were then assessed every $10 \mathrm{~min}$ using pinprick. Only when levels had regressed to below T12 were patients transported to the operating room where the contents of the first epidural syringe were injected (Table I).

Patients in group 1 received $15 \mathrm{ml}$ of epidural $0.5 \%$ bupivacaine injected $35 \pm 1.6 \mathrm{~min}$ before incision, followed by $15 \mathrm{ml}$ of epidural normal saline injected $30 \mathrm{~min}$ after incision. Patients in group 2 received the same treatment but in reverse order; namely, $15 \mathrm{ml}$ of epidural normal saline injected $37 \pm 1.5 \mathrm{~min}$ before incision, followed by $15 \mathrm{ml}$ of $0.5 \%$ bupivacaine injected $30 \mathrm{~min}$ after incision. Opioids were not administered as premedication, at the time of induction of the general anaesthesia, or during the operation.

General anaesthesia. As the contents of the first epidural syringe were injected, and while patients breathed $\mathrm{O}_{2}$, anaesthesia was induced with thiopental $(4-6 \mathrm{mg} / \mathrm{kg})$ and $D$-tubocurare $(3-4.5 \mathrm{mg})$ followed by succinylcholine $(1.5 \mathrm{mg} / \mathrm{kg}$ ) to facilitate tracheal intubation. Anaesthesia was maintained with $50 \% \quad \mathrm{~N}_{2} \mathrm{O}$ with $\mathrm{O}_{2}$ and isoflurane. Paralysis was achieved with pancuronium $(0.1 \mathrm{mg} / \mathrm{kg}$ ). An arterial catheter was used in all patients to monitor arterial pressure and a central venous catheter was occasionally used to monitor fluid balance.

Blood pressure and heart rate were kept within $\pm 20 \%$ of mean pre-operative baseline values with isoflurane and i.v. boluses of phenylephrine and/or propranolol if required. Volume replacement was by means of crystalloid and $5 \%$ albumin. To ensure that patients remained anaesthetized at all times during the surgery, isoflurane was maintained at a minimum level of $0.2 \%$. End-tidal isoflurane was measured by infra-red absorption using a DATEX 254 Airway Gas Monitor (Helsinki, Finland) and was recorded every $15 \mathrm{~min}$ from induction of anaesthesia until the end of surgery.

Neuromuscular blockade was reversed with neostigmine $(0.05$ $\mathrm{mg} / \mathrm{kg})$ and glycopyrrolate $(0.01 \mathrm{mg} / \mathrm{kg})$ at the conclusion of surgery. The trachea was extubated after emergence and upon resumption of spontaneous breathing. Patients received supplemental $\mathrm{O}_{2}$ by mask and were transported to the postanaesthetic care unit (PACU).

\section{Postoperative management}

Patients were assessed immediately upon arrival in the PACU and were connected to a PCA pump system (Abbott Life Care Infuser, Chicago, IL). Every $10 \mathrm{~min}$, patients were asked whether they were in need of pain relief. An affirmative response was followed by a $2 \mathrm{mg}$ i.v. bolus of morphine administered by a nurse observer who was unaware of the group to which the patients had been assigned. This procedure was repeated until the patients were alert enough to begin using the PCA pump. The PCA pump was set to deliver a $1.5-2.0 \mathrm{mg}$ i.v. bolus dose of morphine with a lock-out time of 5-7 min, a maximum dose of $30 \mathrm{mg}$ in any $4 \mathrm{~h}$ period, and no continuous background infusion. This regimen was overseen by the Acute Pain Service and was continued on the ward for $72 \mathrm{~h}$ during which no other analgesics were administered. Morphine $(\mathrm{mg})$ usage for the first $24 \mathrm{~h}$ was calculated on an hourly basis from hard copy records (Abbott TRW Printer Model TP 40) and on a 24 hourly basis thereafter.

\section{Postoperative pain measurement}

A 10-cm VAS (with endpoints labelled 'no pain' and 'worst possible pain') was used to assess pain intensity at rest (VAS-R) 3,6 , $12,24,48$ and $72 \mathrm{~h}$ after the completion of surgery. Pain after movement (VAS-M) was assessed at 24,48 and $72 \mathrm{~h}$ by asking patients to sit up from a lying position and perform two maximal inspirations using an incentive spirometer before rating their pain.

Pain was also assessed at 24, 48, and $72 \mathrm{~h}$ using the McGill Pain Questionnaire (MPQ) (Melzack 1975). The MPQ consists of 20 sets of words, each containing from 2 to 6 adjectives that describe the sensory, affective, or evaluative property of pain. The list of pain descriptors was read to the patient who chose the words that best described his pain at the moment. The MPQ yields 2 global scores, the Pain Rating Index (PRI) and the Present Pain Intensity (PPI). The Total Pain Rating Index (PRI-T) is the sum of the rank values of the descriptors chosen from the 20 sets. The PPI is rated on a scale of $0-5$ as follows: $0=$ no pain, $1=$ mild, $2=$ discomforting, $3=$ distressing, $4=$ horrible, and $5=$ excruciating.

\section{Blood samples}

Blood samples were drawn pre-operatively, $30 \mathrm{~min}$ after surgical incision, at the time of injection of the second epidural syringe and 6 , 12 and $24 \mathrm{~h}$ after completion of surgery. Plasma glucose concentration was measured by a Hitachi analyser (glucose oxydase method) and plasma cortisol concentration by radioimmunoassay.

\section{Data analysis}

Demographic data and clinical variables from groups 1 and 2 were compared using 2-tailed, unpaired $t$ tests (for parametric variables) and Fisher's exact test or chi-squared test for 2-way tables (for non-parametric variables). Plasma levels of cortisol and glucose were analysed by 2-way analysis of covariance (ANCOVA) using Group as the independent samples factor, Time as the repeatedmeasures factor, and the Pre-operative baseline value as the covariate. A significant Group $\times$ Time interaction was further analysed by tests of simple main effects. End-tidal isoflurane was analysed by unpaired 2-tailed $t$ tests at selected time points using Bonferroni's type I error rate correction for multiple tests of significance (i.e., $\alpha$ per number of tests).

VAS pain intensity scores (at rest and after movement) were each analysed by 2-way (Group $\times$ Time) repeated-measures analysis of variance (ANOVA). MPQ total pain (PRI-T) and MPQ PPI were analysed by non-parametric Mann-Whitney $U$ tests. Unpaired, 1tailed $t$ tests with Bonferroni's correction were used to analyse morphine consumed within intervals bounded by the times when pain assessments were carried out. Cumulative morphine consumption was analysed by 1-tailed unpaired $t$ test. Simple linear regression was used to calculate the slope of the least-squares line describing the relationship between cumulative PCA morphine and time after surgery. All data presented are mean \pm SEM unless otherwise specified. $P<0.05$ is considered statistically significant. 


\section{Results}

\section{Patient withdrawals}

Forty-five patients were entered into the study in order to achieve a sample size of 21 patients per group; 3 patients (group 2) were inadvertently given additional analgesics shortly after surgery by nursing staff not involved in the study. These patients were excluded from the study. In addition, 6 patients (5 in group 1 and 1 in group 2) were withdrawn from the study after they received rescue analgesia for bladder spasms. All withdrawals occurred after the $24 \mathrm{~h}$ pain assessment. Thus, there were 21 patients in each group at the $24 \mathrm{~h}$ assessment, 18 patients in group 1 and 21 in group 2 at the $48 \mathrm{~h}$ assessment, and 16 patients in group 1 and 20 in group 2 at the $72 \mathrm{~h}$ assessment. Data up to the time of patient withdrawal were included in the statistical analyses.

\section{Demographic and clinical data}

Demographic and clinical variables for the 2 groups are shown in Tables II and III. The groups were similar in terms of diagnosis, surgical procedure, age and height, but group 2 weighed significantly more than group $1(t(40)=2.02, P=0.05)$.

\section{Pre-operative and intra-operative data}

The 2 groups did not differ significantly with respect to the total epidural test dose of chloroprocaine, the time between the test dose of chloroprocaine and injection of the first epidural syringe, the time between injection of the first epidural syringe and skin incision or duration of surgery. Group 1 received significantly more phenylephrine $(t(40)=2.11, P=0.04)$ and significantly less propranolol $(t(40)=3.25, P=0.002)$ intra-operatively compared with group 2 (Table III).

Fig. 1 shows end-tidal isoflurane measured at 15 min intervals from the time of induction of the general anaesthetic to the end of surgery. End-tidal isoflurane was significantly higher in group $230 \mathrm{~min}$ after injection of the first epidural syringe $(t(22)=3.11, P=$ 0.005 ) and for $60 \mathrm{~min}$ after skin incision (all $t(40)$ $>3.09, P<0.004)$. The point at which the 2 groups no

\section{TABLE 1}

HIGHEST SENSORY LEVEL FOLLOWING EPIDURAL TEST DOSE OF CHLOROPROCAINE SHOWING NUMBER OF PATIENTS IN EACH GROUP ANALGESIC TO PINPRICK

\begin{tabular}{lllllll}
\hline & \multicolumn{3}{c}{ Dermatome } & & \\
\cline { 2 - 7 } & T8 & T9 & T10 & T11 & T12 & L1 \\
\hline Group 1 $(n)$ & - & 1 & 1 & - & 3 & 2 \\
Group 2 $(n)$ & 1 & - & 1 & - & 9 & - \\
\hline
\end{tabular}

TABLE II

FREQUENCY OF DIAGNOSIS AND SURGICAL PROCE DURES FOR THE 2 GROUPS

\begin{tabular}{lcc}
\hline & Group 1 & Group 2 \\
\hline Diagnosis & 18 & 19 \\
Carcinoma of prostate & 1 & - \\
Carcinoma of colon & 1 & - \\
Crohn's disease & - & 1 \\
Diverticulosis & - & 1 \\
Carcinoma of stomach & 1 & - \\
Cholangiocarcinoma & & \\
Procedure & 17 & 18 \\
Radical prostatectomy & 3 & 2 \\
Colon resection & - & 1 \\
Partial gastrectomy & 1 & - \\
Bile duct tract excision & 1 & 1 \\
Pelvic lymphadenectomy & & \\
\hline
\end{tabular}

longer differ significantly corresponds approximately to $45 \mathrm{~min}$ after injection of the second epidural syringe which contained saline in group 1 and bupivacaine in group 2. These results provide indirect support for the effectiveness of the epidural blockade in both groups.

\section{Stress response data}

Fig. 2 shows plasma glucose and cortisol concentrations for the 2 groups before, during and after surgery. The test of the homogeneity of slopes assumption (i.e., Group $\times$ Covariate interaction) carried out prior to the ANCOVA indicated that the slope of the regression line of the baseline measures (of glucose and cortisol) onto the postincisional measures did not differ significantly between the 2 groups. Results of the ANCOVA for glucose showed a marginally significant main effect of group $(F(1,36)=3.58, P=0.06)$ indicating that from the time of the first sample after incision onwards, mean plasma concentration of glucose was higher in group $2(6.67 \pm 0.27 \mathrm{mmol} / \mathrm{l})$ than in group 1 $(6.22 \pm 0.15 \mathrm{mmol} / \mathrm{l})$. For cortisol, the ANCOVA showed a significant Group $\times$ Time interaction $(F(3$,

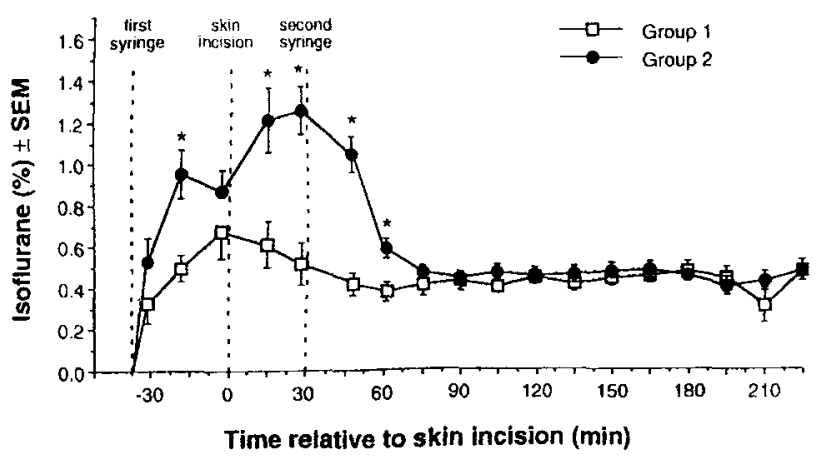

Fig. 1. Endtidal isoflurane (\%) for the 2 groups. ${ }^{*} P<0 .(105$. 

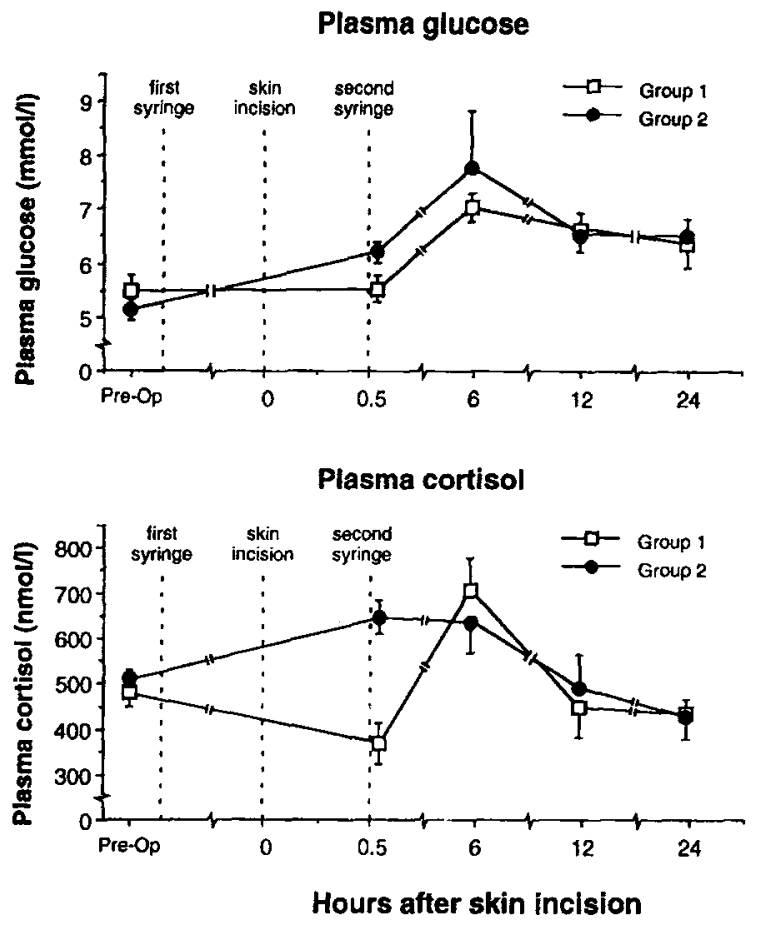

Fig. 2. Plasma glucose and cortisol for the 2 groups before and after surgery.

$108)=4.92, P=0.003$ ). Simple effects indicated that mean plasma cortisol concentration was significantly higher in group $2(628.7 \pm 38.7 \mathrm{nmol} / \mathrm{l})$ than group 1 $(354.8 \pm 44.8 \mathrm{nmol} / \mathrm{l}) 30 \mathrm{~min}$ after incision $(F(1,36)=$ 20.6, $P=0.0001$ ) but not at later times.

\section{Postoperative pain}

Fig. 3 shows pain scores at rest (VAS-R) and after movement (VAS-M). Results of the ANOVAs showed a significant time effect for VAS-R $(F(5,170)=34.1$, $P=0.0001)$ and VAS-M $(F(2,68)=9.20, P=0.0003)$

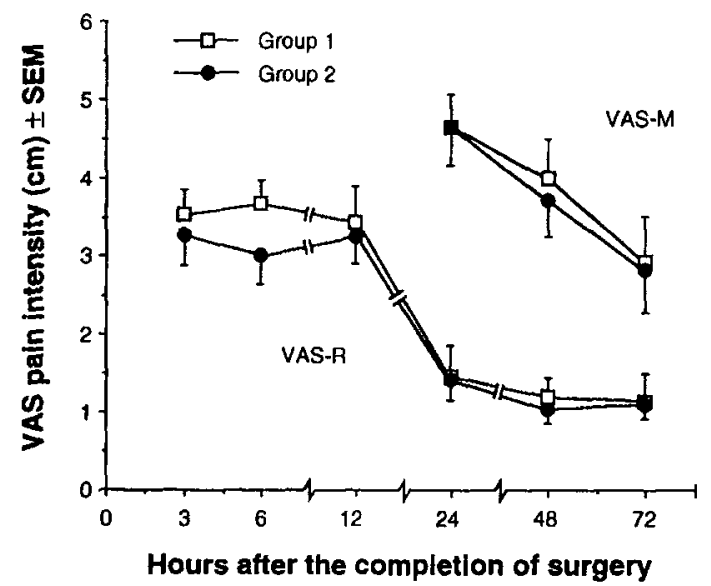

Fig. 3. Visual analogue pain scores at rest (VAS-R) and after standard mobilization exercises (VAS-M).
TABLE III

MEAN (SEM) DEMOGRAPHIC AND CLINICAL VARIABLES FOR THE 2 GROUPS

\begin{tabular}{|c|c|c|c|c|c|}
\hline Variable & Group & & Grou & & $P$ \\
\hline Age (years) & 61.3 & $(2.2)$ & 60.0 & $(1.7)$ & NS \\
\hline Weight (kg) & 79.1 & (2.3) & 86.3 & (2.7) & 0.05 \\
\hline Height $(\mathrm{cm})$ & 172.9 & (1.7) & 176.0 & $(1.4)$ & NS \\
\hline $\begin{array}{l}\text { Test dose of } 3 \% \\
\text { chloroprocaine }(\mathrm{ml})\end{array}$ & 3.0 & $(0.1)$ & 3.1 & $(0.2)$ & NS \\
\hline $\begin{array}{l}\text { Time (min) between } \\
\text { test dose and } \\
\text { first syringe }\end{array}$ & 69 & $(7.8)$ & 50 & (5.1) & NS \\
\hline $\begin{array}{l}\text { Time (min) between } \\
\text { first syringe } \\
\text { and skin incision }\end{array}$ & 35 & (1.6) & 37 & (1.5) & NS \\
\hline $\begin{array}{l}\text { Duration of surgery } \\
\text { (min) }\end{array}$ & 170 & $(9.6)$ & 193 & $(7.3)$ & NS \\
\hline $\begin{array}{l}\text { Arrival time in } \\
\text { PACU (h:min) }\end{array}$ & $13: 44$ & $4(26)$ & $13: 0$ & (19) & NS \\
\hline $\begin{array}{l}\text { Phenylephrine }(\mu \mathrm{g}) \\
\text { Propranolol }(\mathrm{mg})\end{array}$ & $\begin{array}{l}340 \\
0.18\end{array}$ & $\begin{array}{l}(117.9) \\
(0.07)\end{array}$ & $\begin{array}{r}80.1 \\
0.7\end{array}$ & $\begin{array}{l}(35.6) \\
(0.14)\end{array}$ & $\begin{array}{l}0.04 \\
0.002\end{array}$ \\
\hline
\end{tabular}

indicating that pain intensity decreased over the course of the study, but the group main effect and the Group $\times$ Time interaction were non-significant for both variables.

Table IV contains the MPQ PRI-T and the PPI for the 2 groups on the 3 postoperative days. Although the average PPI rating was low for both groups, corresponding to the descriptor 'mild', it was significantly lower in group 1 than group $224 \mathrm{~h}$ after surgery $(z=2.00, P=0.05)$. In addition, at the $72 \mathrm{~h}$ assessment, both the PRI-T $(z=3.01, P=0.003)$ and PPI $(z=2.20, P=0.03)$ were significantly lower in group 1 than group 2. Table $\mathrm{V}$ shows the MPQ adjectives chosen by $33 \%$ or more of patients in the 2 groups. There was a tendency for group 2 patients to choose

TABLE IV

MPQ SCORES FOR THE 2 GROUPS 24, 48 AND 72 h AFTER SURGERY

\begin{tabular}{llll}
\hline & Group 1 & Group 2 & $P$ \\
\cline { 2 - 3 } & Mean (SD) & Mean (SD) & \\
\hline 24 h assessment & & & \\
PRI-T & $9.6(13.0)$ & $8.3(5.6)$ & NS \\
PPI & $0.7(0.6)$ & $1.2(0.7)$ & 0.05 \\
n & 16 & 20 & \\
48 h assessment & & & \\
PRI-T & $4.4(3.4)$ & $7.2(5.3)$ & NS \\
PPI & $0.7(0.8)$ & $1.0(0.8)$ & NS \\
n & 14 & 18 & \\
72 h assessment & & & \\
PRI-T & $2.5(2.4)$ & $7.9(6.9)$ & 0.003 \\
PPI & $0.3(0.5)$ & $1.1(0.9)$ & 0.03 \\
n & 10 & 18 & \\
\hline
\end{tabular}


TABLE $V$

MPQ DESCRIPTORS CHOSEN BY 33\% OR MORE OF PATIENTS IN THE 2 GROUPS

\begin{tabular}{lllcl}
\hline Time & MPQ & Descriptor & $\begin{array}{c}\text { Group } 1 \\
(\geqslant 33 \%)\end{array}$ & $\begin{array}{l}\text { Group } 2 \\
(\geqslant 33 \%)\end{array}$ \\
\cline { 2 - 5 } & Class & dull & - & 40 \\
Day I & PRI-Sensory & sore & - & 40 \\
& & tender & 50 & 55 \\
& \multirow{2}{*}{ PRI-Affective } & tiring & - & 35 \\
& PPI & mild & 57 & 50 \\
& & discomforting & - & 35 \\
Day 2 & PRI-Sensory & tender & 43 & 50 \\
& & dull & - & 39 \\
& PPI & discomforting & - & 33 \\
Day 3 & PRI-Sensory & dull & - & 39 \\
& & sore & - & 44 \\
& & tender & - & 39 \\
& PRI-Evaluative & annoying & - & 33 \\
& PPI & mild & 33 & 40 \\
\hline
\end{tabular}

more words to describe their pain than group 1 patients. In addition, there is a consistency between the groups in their choice of descriptors. All descriptors endorsed by $33 \%$ or more of patients in group 1 were also endorsed by $33 \%$ or more of patients in group 2 although the latter group chose more words.

\section{PCA morphine consumption}

Fig. 4 shows PCA morphine consumption within the intervals bounded by the times when pain assessments were carried out. Morphine use in group 1 was reduced by $68 \%$ between 12 and $24 \mathrm{~h}$ after surgery. Group 1 $(19.7 \pm 1.7 \mathrm{mg})$ self-administered significantly less morphine than group $2(33.0 \pm 3.7 \mathrm{mg})(t(39)=3.31, P=$ $0.001)$. This $12-24 \mathrm{~h}$ difference in morphine consumption was also significant when patient weight was used as a covariate in an ANCOVA $(F(1,38)=7.4, P=$ $0.01)$. In addition, cumulative morphine use by group 1

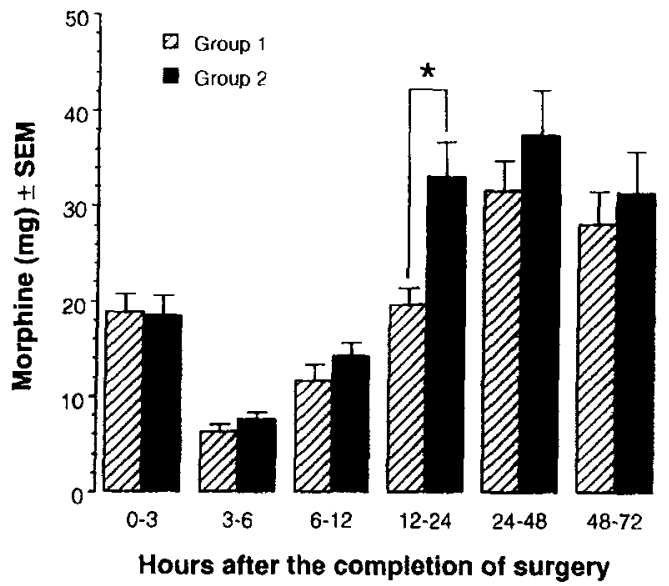

Fig. 4. PCA morphine consumption within time intervals bounded by VAS pain assessments ${ }^{*} P<0.001$

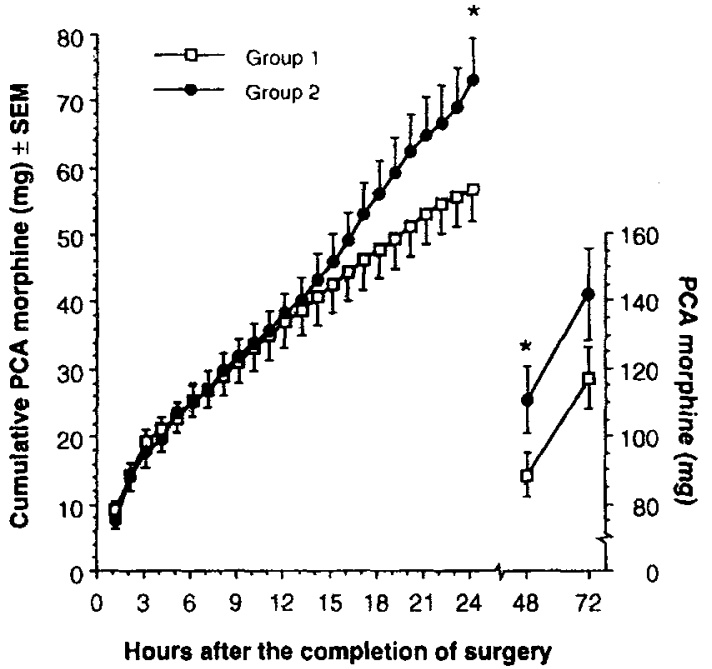

Fig. 5. Cumulative PCA morphine consumption. ${ }^{*} P<0.04$.

was significantly lower than group 2 at the $24 \mathrm{~h}(55.2 \pm$ $4.7 \mathrm{mg}$ vs. $71.7 \pm 6.1 \mathrm{mg}$, for groups 1 and 2 , respectively, $t(40)=2.1, P=0.02)$ and $48 \mathrm{~h}(86.8 \pm 6.3 \mathrm{mg}$ vs. $108.9 \pm 9.8 \mathrm{mg}$, for groups 1 and 2 , respectively, $t$ (36) $=1.9, P=0.04$ ) assessments, but not at the end of the study, $72 \mathrm{~h}$ after surgery $(115.3 \pm 9.0 \mathrm{mg}$ vs. 140.2 $\pm 13.5 \mathrm{mg}$, for groups 1 and 2 , respectively, $t(33)=1.5$, $P=0.08$ ). The $72 \mathrm{~h}$ mean difference in morphine amounted to $24.9 \pm 11.5 \mathrm{mg}$ which represents a $22 \%$ reduction in the total morphine dose.

The slopes of the regression lines relating cumulative morphine and time were calculated for each group from 12 to $24 \mathrm{~h}$ and from 24 to $72 \mathrm{~h}$ after surgery. The mean hourly rate of morphine consumption over the $12-24 \mathrm{~h}$ period was $1.6 \pm 0.15 \mathrm{mg} / \mathrm{h}$ and $2.8 \pm 0.31$ $\mathrm{mg} / \mathrm{h}$ for groups 1 and 2 , respectively. Over the 24-72 $\mathrm{h}$ period, the rate of morphine consumption was virtually identical in the 2 groups $(1.4 \pm 0.18 \mathrm{mg} / \mathrm{h}$ and $1.3 \pm 0.13 \mathrm{mg} / \mathrm{h}$ for groups 1 and 2 , respectively). The coefficient of determination $\left(r^{2}\right)$ for each regression line was greater than or equal to 0.99 , indicating an extremely strong linear relationship between cumulative morphine and time.

\section{Complications}

No complications or adverse effects were observed in any of the patients.

\section{Discussion}

The results of the present study support the hypothesis that postoperative pain and PCA morphine consumption are reduced by pre- versus postincisional lumbar epidural bupivacaine. The morphine-sparing effect was most pronounced between 12 and $24 \mathrm{~h}$ after surgery (Figs. 4 and 5) long after the anticipated clini- 
cal duration of action of the lumbar epidural bupivacaine. Overall, the cumulative morphine-sparing effect $72 \mathrm{~h}$ after surgery amounted to a $22 \%$ reduction in dose. The absence of a difference in VAS pain scores indicates that patients in both groups were titrating morphine consumption to a comparable pain intensity, suggesting that the additional morphine used by patients in group 2 was required to bring their VAS pain scores down to a level comparable to that of patients in group 1 . Consistent with the 24,48 , and $72 \mathrm{~h}$ VAS pain score ratings, the average MPQ PPI in both groups corresponded to the descriptor 'mild'. Nevertheless, the PPI (at 24 and $72 \mathrm{~h}$ ) and PRI-T (at $72 \mathrm{~h}$ ) were higher in group 2 (Table IV) and a greater proportion of patients in group 2 endorsed more pain descriptors from the MPQ (Table V). These inter-group differences in pain as measured by the MPQ are not inconsistent with the results of the VAS scores. The MPQ appears to provide a more sensitive measure of mild postoperative pain than does a simple VAS which assesses pain intensity only since patients can be more precise in describing their experience. The MPQ scores may reflect a relative hyperalgesia among group 2 patients but interpretation is complicated by missing data (see Table IV). Further research is required to clarify the role of the MPQ in studies of pre-emptive analgesia.

The observed patterns of plasma glucose and cortisol levels are consistent with previous data on the modification of the stress response by epidural local anaesthesia in patients undergoing lower abdominal surgery (Kehlet 1988). The transient nature of the modified stress response in group 1 parallels the duration of action of the local anaesthetic blockade and may reflect modulation of the sympathoadrenal response, although plasma catecholamines were not assayed. The relationship between the surgical stress response and the development of postoperative pain in the context of pre-emptive analgesia has not previously been explored. Pre-incisional local anaesthetic blockade delayed the neuroendocrine response to surgery but it did not attenuate the magnitude of the response (Fig. 2). The lower pain scores and reduced morphine consumption in group 1 occurred when plasma cortisol and glucose levels in the 2 groups were no longer significantly different.

Taken together, the results of the present study support the idea that the injury barrage associated with surgical incision and subsequent noxious intra-operative events sensitizes spinal cord cells so that subsequent inputs from the wound are amplified leading to heightened pain and an increased requirement for postoperative PCA morphine. The significantly greater consumption of morphine by group 2 beginning $12 \mathrm{~h}$ after surgery parallels the results of our previous study comparing pre- versus postincisional lumbar epidural fentanyl in patients undergoing lateral thoracotomy (Katz et al. 1992). The pre-emptive effect reported by Richmond et al. (1993) was also observed within the first $24 \mathrm{~h}$ after surgery although the pattern of morphine consumption over time was not presented. In the present study, the greatest divergence in the hourly rate of morphine consumption occurred within the second $12 \mathrm{~h}$ period after surgery with groups 1 and 2 self-administering approximately $1.6 \mathrm{mg} / \mathrm{h}$ and 2.8 $\mathrm{mg} / \mathrm{h}$ respectively. From $24 \mathrm{~h}$ onward, the least-squares straight lines were virtually parallel.

Although the majority of studies of pre-emptive analgesia have involved local anaesthetic agents (either alone or in combination with an opioid), very few have evaluated the effects on postoperative pain and analgesic consumption of administering local anaesthetics before versus after incision or surgery. As noted in the introduction, studies in which the control condition consists of a group of untreated or placebo-treated patients, have found marked differences in pain or analgesic use in favour of the treated group. In contrast, when the very same treatment is carried out after incision or surgery, the results have generally failed to show an advantage of the pre-treated group. Results consistent with the present findings include pre-incisional local anaesthetic nerve block (Ringrose and Cross 1984) or pre-incisional local anaesthetic infiltration (Ejlersen et al. 1992) which reduced postoperative opiate dose (Ringrose and Cross 1984), increased the time to first analgesic request and reduced the number of patients requiring supplemental analgesics (Ejlersen et al. 1992) when compared with the same treatment initiated after incision or surgery.

Failure to demonstrate a pre-emptive analgesic effect may be due to a continued action of the local anaesthetic at the time of pain assessment (Rice et al. 1990) or the administration to all patients of opioids as premedication (Pryle et al. 1993) or at induction of the general anaesthetic (Dahl et al. 1992; Dierking et al. 1992) and during the surgery (Dierking et al. 1992). A postoperative opioid sparing effect has recently been demonstrated after $10 \mathrm{mg}$ i.v. morphine was administered at induction of the general anaesthetic compared with $10 \mathrm{mg} \mathrm{im}$ morphine administered $1 \mathrm{~h}$ before surgery or $10 \mathrm{mg}$ i.v. morphine at the time of closure of the peritoneum (Richmond et al. 1993). In addition, secondary hyperalgesia surrounding the wound was reduced in the pre-treated groups. The results of the study by Richmond et al. (1993) support the argument that i.v. administration of $\mu$-opioid agonists as part of the general anaesthetic regimen in studies of pre-emptive analgesia may also pre-empt postoperative pain. This practice may unwittingly lead to a negative finding when pre-incisional and post-surgical regional techniques are compared. A possible exception is the negative result of Pryle et al. (1993) since the opioid pre- 
medication ( $7.5-10 \mathrm{mg}$ im morphine $1 \mathrm{~h}$ before surgery) was almost identical to the i.m. premedication condition in the study by Richmond et al. (1993) reported above which (relative to the i.v. post-condition) failed to pre-empt postoperative pain.

Finally, it has been hypothesized that failure to demonstrate a pre-emptive analgesic effect may reflect the induction of central sensitization in all patients after the pharmacological action of the pre-operative agent has disappeared (Dierking et al. 1992) or in the case of continuous epidural infusion due to insufficient afferent blockade in the postoperative period (Dahl et al. 1992). Since this suggestion is usually invoked to explain why a pre-emptive analgesic effect was not demonstrated, a negative result does not provide the opportunity to test the hypothesis. Partial support for the possibility that postoperative inflammatory inputs from the wound may initiate to a state of central sensitization was recently reported by Richmond et al. (1993). Movement-associated pain scores $48 \mathrm{~h}$ after surgery were higher in the i.v. 'pre' group, suggesting that the extra morphine used by patients in the i.v. 'post' group during the first $24 \mathrm{~h}$ after surgery preempted pain in the second $24 \mathrm{~h}$ period. However, as noted (Katz 1993), this finding is difficult to interpret since the nature and quantity of analgesics received in the second $24 \mathrm{~h}$ was not reported. The results of the present study do not show this trend. The rate of morphine consumption from $24 \mathrm{~h}$ after surgery onward was virtually identical in the 2 groups even though MPQ scores in the late postoperative period were greater in group 2. Thus, our results do not support the suggestions (1) that a state of central sensitization (as measured by inter-group differences in pain scores and morphine consumption) which may have developed after surgery in group 1 due to inflammation, was sufficient to overcome the pre-emptive effect relative to group 2 , or (2) that the additional morphine used by group 2 patients in the first $48 \mathrm{~h}$ was sufficient to pre-empt subsequent pain relative to group 1 patients. Nevertheless, the results after $24 \mathrm{~h}$ must be interpreted cautiously since 5 patients in group 1 and 1 patient in group 2 were dropped from the study after receiving rescue analgesia for bladder spasms. Whether this pattern of patient withdrawals differentially affected pain scores and PCA requirements in the 2 groups cannot be determined.

The present study was designed to assess whether pre-incisional lumbar epidural bupivacaine would lead to reduced pain and analgesic consumption when compared with postincisional administration of the same agent by the same route. Opioids were deliberately not administered at any time before or during the surgery in order to evaluate the pre-emptive effect of the local anaesthetic alone. The omission of opioids raises the issue of the clinical releciance of the general anaesthetic regimen, since lower abdominal surgery is usually performed with an opioid premedication and intra-operative opioids even when epidural local anaesthesia is also administered. The $22 \%$ reduction in the total dose of morphine and the slightly lower MPQ pain scores are clearly advantageous to the patients. Although small, we consider these effects to be clinically significant. However, we do not know whether similar reductions would have been achieved in the postincisional group had intra-operative opioids been administered to all patients as part of the general anaesthetic regimen.

We have not identified any clinically significant disadvantages to pre-incisional administration of epidural local anaesthesia that are not also associated with postincisional administration. The most common adverse effect, hypotension, may develop whether the epidural blockade is established before or after the induction of general anaesthesia (Germann et al. 1979) and can be managed by pre-block hydration and intraoperative administration of vasoconstrictors. Although the beneficial effects of this pre-emptive regimen are relatively small, coupled with the reduced intra-operative anaesthetic requirement (Fig. 1) and attenuated stress response (Fig. 2), the pre-operative placement and use of the epidural catheter is justified on clinical grounds.

In conclusion, the results of the present study suggest that single-shot pre-emptive epidural bupivacaine is associated with a short-term opioid-sparing effect which is most pronounced between 12 and $24 \mathrm{~h}$ after surgery and is still evident at $48 \mathrm{~h}$. Extending the pre-operative blockade into the postoperative period may prolong the initial advantage conferred by preemptive epidural local anaesthesia.

\section{Acknowledgements}

The authors are grateful for the help provided by Marla Jackson, and the staff of the Departments of Anaesthesia, Urologic Surgery and the PACU. Supported by a Medical Research Council of Canada (MRC) Scholarship and MRC Grant MT-12052 to Joel Katz.

\section{References}

Coderre, T.J., Vaccarino, A.L. and Melzack, R., Central nervous system plasticity in the tonic pain response to subcutaneous formalin injection, Brain Res., 535 (1990) 155-158.

Coderre, T.J., Katz, J., Vaccarino, A.L. and Melzack, R., Contribution of central neuroplasticity to pathological pain: review of clinical and experimental evidence, Pain, 52 (1993) 259-285.

Dahl, J.B. and Kehlet, $H$., The value of pre-emptive analgesia in the treatment of postoperative pain, Br. J. Anaesth., 70 (1993) 434439. 
Dahl, J.B., Hansen, B.L., Hjortsø, N.C., Erichsen, C.J., Møiniche, S. and Kehlet, $\mathrm{H}$., Influence of timing on the effect of continuous extradural analgesia with bupivacaine and morphine after major abdominal surgery, Br. J. Anaesth., 69 (1992) 4-8.

Dallal, G.E., DESIGN: A supplementary module for SYSTAT and SYGRAPH, SYSTAT, Evanston, IL, 1988.

Dickenson, A.H. and Sullivan, A.F., Subcutaneous formalin-induced activity of dorsal horn neurones in the rat: differential response to an intrathecal opiate administered pre- or post-formalin, Pain, 30 (1987) 349-360.

Dierking, G.W., Dahl, J.B., Kanstrup, J., Dahl, A. and Kehlet, H., Effect of pre- vs. postoperative inguinal field block on postoperative pain after herniorraphy, Br. J. Anaesth., 68 (1992) 344-348.

Ejlersen, E., Bryde Anderson, H., Eliasen, K. and Mogensen, T., A comparison between preincisional and postincisional lidocaine infiltration and postoperative pain, Anesth. Analg., 74 (1992) $495-498$.

Germann, P.A.S., Roberts, J.G. and Prys-Roberts, C., The combination of general anaesthesia and epidural block. I. The effects of sequence of induction on haemodynamic variables and blood gas measurements in healthy patients, Anaesth. Intens. Care, 7 (1979) 229-238.

Katz, J., Preop analgesia for postop pain, Lancet, 342 (1993) 65-66.

Katz, J., Kavanagh, B.P., Sandler, A.N., Nierenberg, H., Boylan, J.F., Friedlander, M. and Shaw, B.F., Preemptive analgesia: clinical evidence of neuroplasticity contributing to post-operative pain, Anesthesiology, 77 (1992) 439-446.

Kehlet, H., Modification of responses to surgery by neural blockade: clinical implications. In: M.J. Cousins and P.O. Bridenbaugh (Eds.), Neural Blockade in Clinical Anesthesia and Management of Pain, 2nd edn., J.B. Lippincott, Philadelphia, PA, 1988, pp. 145-188.

McQuay, H.J., Pre-emptive analgesia, Br. J. Anaesth., 69 (1992) 1-3. Melzack, R., The McGill Pain Questionnaire: major properties and scoring methods, Pain, 1 (1975) 277-299.

Pryle, B.J., Vanner, R.G., Enriquez, N. and Reynolds, F., Can pre-emptive epidural blockade reduce postoperative pain following lower abdominal surgery?, Anaesthesia, 48 (1993) 120-123.

Rice, L.J., Pudimat, M.A. and Hannallah, R.S., Timing of caudal block placement in relation to surgery does not affect duration of postoperative analgesia in paediatric ambulatory patients, Can. $J$. Anaesth., 37 (1990) 429-431.

Richmond, C.E., Bromley, L.M. and Woolf, C.J., Preoperative morphine pre-empts postoperative pain, Lancet, 342 (1993) 73-75.

Ringrose, N.H. and Cross, M.J., Femoral nerve block in knee joint surgery, Am. J. Sports Med., 12 (1984) 398-402.

Wall, P.D., The prevention of post-operative pain, Pain, 33 (1988) 289-290

Wall, P.D., To what would Gaston Labat be attending today?, Reg. Anesth., 14 (1989) 261-264.

Woolf, C.J., Central mechanisms of acute pain. In: M.R. Bond, J.E. Charlton and C.J. Woolf (Eds.), Proc. VIth World Congress on Pain, Elsevier, Amsterdam, 1991, pp. 25-34.

Woolf, C.J. and Chong, M.S., Preemptive analgesia: treating postoperative pain by preventing the establishment of central sensitization, Anesth. Analg., 77 (1993) 362-379.

Woolf, C.J. and Wall, P.D., Morphine-sensitive and morphine-insensitive actions of $\mathrm{C}$-fibre input on the rat spinal cord, Neurosci. Lett., 64 (1986) 221-225. 